\title{
How do Viruses Cause Different Diseases? \\ "From Transient Infection to Chronic Disease"
}

\author{
Raghavendra RMV1*, Bala S1, Sripada Pallavi T2, Krishna Sowmya \\ $\mathbf{M}^{3}$, Ramanaiah $\mathrm{CJ}^{3}$, Fatteh $\mathrm{S}^{1}$, Krishnateja $\mathrm{C}^{1}$, Hn $\mathbf{R}^{1}$ and Sateesh \\ Babu $\mathbf{A}^{1}$
}

${ }^{1}$ Avalon University School of Medicine, Curacao, Central America

Review Article

Volume 2 Issue 6

Received Date: April 27, 2018

Published Date: May 07, 2018

${ }^{2}$ Apollo Institute of Medical Science and Research Institute, Jubilee Hills, Hyderabad, Telangana, India

${ }^{3}$ Burjil Hospital, Abu Dhabhi, UAE

*Corresponding author: Raghavendra Rao MV, Professor of Microbiology and Immunology, Dean of Student Affairs \& Research Director, Avalon University School of Medicine(AUSOM), Sta. Rosaweg 122-124, Willemstad, Curacao, Central America, Tel: +5999 788-8008; Email: reachdrmvrrao@gmail.com

\section{Abstract}

There are many types of viruses that cause a wide variety of viral diseases. Viruses evolve rapidly and hence the human virome changes constantly. The human virome is a part of our bodies and will not always cause harm. Many latent and asymptomatic viruses are present in the human body all the time. Viruses infect all life forms; Long long ago, only two polyomaviruses were known to infect humans. Now scientists identified several human polyomavirus serotypes, that are responsible in causing neurological or renal damage in immunosuppressed and AIDS patients to skin cancers. Most of these polyomaviruses infect a majority of people during childhood and are then silently carried until a weakened immune system and cause serious complications.

Keywords: Virome; Polyomavirus; CDC; Cytopathic Effects (CPE); Lytic Infection; Severe Acute Respiratory Syndrome

\section{Introduction}

The goal of medical virology is consist isolating and / or characterizing one or several viruses responsible for some human pathologies by various direct or indirect techniques [1]. As per World health organization (WHO) and centre for Disease control and prevention (CDC) reports global diseases burden is raising and virus infection. 0n with associated diseases is major factor in raising global diseases burden [2]. Viruses are highly contagious intracellular pathogens present ubiquitously in nature. Since the ancient time infectious disease are leading cause of large scale human casualties and among all the infectious diseases virus based infections are much higher nearly $50 \%$ of all global infections [3]. The newly emerged and re-emerged virus infections are prevailing 


\section{Virology \& Immunology Journal}

and a serious negative impact of human health. Further, co-infections become another issues with the emerging infectious viral diseases reported as major challenge in prevention and cure [3]. The new variants and serotype are continuously affecting a large number of human populations and lack of diagnostic devices and protocol further enhanced global diseases burden [4]. Only a fraction of viruses present in nature have been profiled and catalogued till now and the newly emerged and reemerged viral infections have enhanced the problem of global disease burden.

For most virus the molecular basis for the specificity is that a particular surface molecule known as the viral receptor must be found on the host cell surface for the virus to attach [5]. Also, metabolic and host cell immune response different cell types based on differential gene expression are likely a factor in which cells a virus may target for replication. The permissive cell must make the substances that the virus needs or the virus will not able to replicate there [6]. The viruses routinely infect animal, plant and microbes and cause large number diseases. The selection of expressing on surface of viral capsid. In general, viral capsid contains a large number glycoprotein find suitable host based pathogen infraction [7]. For an example in case of human deficiency virus (HIV) the surface protein on viral capsid called as glycoprotein (GP41.gp120 and gp160) first scan for CCR5 and CXCR 5 receptor present on immune cells $[7,8]$. Similarly, other viruses also recognize their host based on molecular interactions. A confirmation of host only allows other steps of infections including injection of genetic material, replication of genetic material, assembly of new viral capsid surface are key factor in determining its host and also useful in clinical virology and diagnostic distant host as well. In case of multiple hosts, primary host act as carrier or reservoir and secondary host is mainly associated with diseases [9].

The host-pathogen interaction is defined as how microbes or viruses sustain themselves within host organisms on a molecular, cellular, organism" or population level [10]. In the process of host pathogen interactions several molecules from host and pathogen involve to complete infection and subsequently onset of diseases. Here, pathogens undergo for host pathogen interactions for many reasons; first to take control over host cellular machinery for their own use [11]. Here, the molecular interactions allow a virus to encode specific proteins for cellular control which is only possible after complete understanding of host Cell physiology and which is possible only after host pathogen interactions.
Secondly the host pathogen interactions are also important for virus to escape from host immune response by modulating its genome and proteins [12]. Several viruses such as human immune deficiency viruses [acquired immune deficiency syndrome] flu viruses; H1N1, H5N1, [flu] varicella zoster [chickenpox] and HERPERVIRIDIAE [HERPES SIMPLEX VIRUSES] can hide from the immune system in neurons and non neuronal cells where they may persist for many years ,before emerging In pathogenic form when the host has a lower resistance [13]. As a result, pathogens find an ideal environment for its growth and replication. The role of the host is also important in the process of host pathogen interactions and equally responsible for infection and diseases [14]. The host pathogen interactions are mutual cross talk between a host and a invader pathogen and driven by a series of molecules [15]. On the contrary, host try to read molecular signature of invading pathogen and activate its immune system for complete removal of pathogen [16].

Viral pathogenesis is the study of how biological viruses cause diseases in their target hosts, usually carried out at the cellular or molecular level [17]. The factors that determine the viral transmission, multiplication, and development of disease in the host involve complex and dynamic interactions between the virus and the susceptible host [18]. Viruses cause disease when they breach the host's primary physical and natural protective barriers; evade local, tissue, and immune defense; spread in the body and destroy cells either directly or via bystander immune and inflammatory responses [19]. Viral infection was long thought to produce any acute clinical disease but other host responses are being increasingly recognized [20].

The virus infected cells can respond to virus infection in 3different ways including no apparent change, cytopathic effects (CPE) and death and loss of growth control (transformation) [21].

Although viral pathogens are not similar to bacterial pathogens in terms of structure, some of the properties that contribute to their virulence are similar. Viruses use adhesions to facilitate adhesion to host cells , and certain envelope viruses rely on antigenic variation to avoid the host immune defences [22]. The interaction of viral adhesions with specific cell receptors defines the tropism (preferential targeting) of viruses for specific cells, tissues, organs in the body [23]. Another viral adhesion is the glycoprotein gp20, found on HIV. For HIV to infect cells of the immune system, it must interact with two 
receptors on the surface of cells. The first interaction involves binding between gp120 and the CD4 cellular marker that is found on some essential immune system cells [24].

The adenoviruses are DNA viruses and largely associated with diseases of respiratory tract. These viruses are comparative less pathogenic with retroviruses..However, newly emerged serotypes can also cause several other diseases apart from respiratory tract infection $[25,26]$. Adenoviruses are a group of viruses that can infect the membranes (tissue linings) of the respiratory tract, eyes, intestines, urinary tract, and nervous system [27,28]. They account for about 10percent of fever-related illnesses and acute respiratory infections in kids and are a frequent cause of diarrhoea. Upon infection with adenovirus, one of three different interactions with the cells may occur [29]. THE first is lytic infection, and the second is latent infection, the exact mechanism of which is unknown, which frequently involves asymptomatic infection of lymphoid tissue [30]. Thereafter, adenovirus produces potent E1A proteins that immortalize primary rodent cells by altering cellular transcription, ultimately leading to deregulation of apoptosis and malignant transformation [31].

Conjunctivitis caused by adenovirus infection is a more serious manifestation of the virus. The serotypes that cause conjunctivitis infections can be transmitted in swimming pools with insufficient chlorination or from eye equipment that has not been properly sterilized [32].

Occasionally adenovirus can cause patients to have painful and bloody urine. The differential diagnosis includes bacterial cystitis, stones, and tumors. Hematuria (urine containing blood) can be distinguished from more serious infections by imaging tests; adenovirus infection usually does not cause the Patient to have renal or bladder abnormalities when they are imagined with Xrays [33].

Gastrointestinal symptoms, including abdominal pain and diarrhoea have been reported and are caused by serotypes 40 and 41 . In children, respiratory symptoms are also commonly found with gastrointestinal infections. adenovirus is also associated with intussusceptions in younger children [34].

Notable human diseases caused by RNA viruses include Ebola hemorrhagic fever, SARS, the common cold, influenza, hepatitis $\mathrm{C}$, West Nile fever, polio and measles [35]. RNA viruses are any group of viruses whose nucleic acid core is composed of RNA; this includes the picornaviruses, retroviruses, and paramyxovirsues. An RNA virus is a virus that either uses RNA intermediate during replication. For example Hepatitis B virus is classified as an RNA virus, even though its genome is double stranded DNA, because the genome is transcribed into RNA during replication [36].

\section{Major Advances and Discoveries}

\section{The major diagnostic tests are employed in detection of viruses in the laboratory}

1. Electron Microscopy is used for observing morphology of the specimen,

2. Observing inclusion bodies under light microscope,

3. Immunofluorescence, ELISA techniques can be used for Antigen detection,

4. For the direct detection of viral genomes, Molecular techniques,

5. Observing CPE (Cytopathic Effects) inclusion bodies,

6. Cell Cultures,

7. Animal experiments,

8. Serological tests for detection of rising titres of Antibody,

9. Neutralization tests,

10. Immuno fluorescence techniques (IF),

11. Complement fixation tests,

12. Immuno fluorescence techniques,

13. Complement fixation tests (CFT),

14. Haemagglutination tests,

15. ELISA,

16. Radioimmuno assay PCR is the gold standard approach to evaluate viral replication. Some less-costly molecular assays are being developed, including a new semi-quantitative real-time PCR approach able to discriminate samples can be used.

\section{History and Mechanism}

Louis Pasteur and Edward Jenner developed the first vaccines to protect against viral infections, without knowing viruses helped to observe the virus particles, especially bacteriophages. Smallpox and measles viruses are among the oldest that infect humans. Louis Pasteur and Edward Jenner were the first to develop vaccines to protect against viral infections. Other epidemics of viral diseases such as mumps, rubella and polio, also first occurred at this time. Herpes viruses first infected the ancestors of modern. Discovery of several important human viruses including Varicella zoster virus, the paramyxoviruses, which include measles virus, and 
respiratory syntactical virus and the rhinoviruses that cause the common cold. There were epidemics of poliomyelitis that were only controlled following the development of a vaccine in the 1950s. HIV is one of the most pathogenic new viruses to have emerged in centuries. These discoveries have continued in the 21st century as new viral diseases such as SARS virus.

\section{Significant Gap in Research}

Notwithstanding the tools able to successfully prevent, suppress, and cure viral diseases, the most efficient way requires considerable research. Vaccine coverage should be increased to all regions of the world, while the reasons for reluctance to vaccinate could provide insights on accomplishing this goal. Cheaper and easier technology to test for viral diseases should be developed and used in campaigns to increase infection awareness in key populations. Treatment must be accessible to infected individuals to prevent disease progression. Finally, it is likely that a combination of these tools is required for elimination of viral diseases.

\section{Current Debate}

Within a decade, smallpox, which was responsible for more deaths would also disappear as a threat. And yet infectious diseases, which can cross the globe long before symptoms arise, remain a constant presence. H.I.V. has killed tens of millions of people. Ebola, while far less likely to cause a pandemic, has killed more than seven thousand people and has caused economic damage in Africa. SARS also produced potential threats. Influenza, perhaps the deadliest virus, particularly could kill tens or even hundreds of millions. The H1N1 epidemic in 2009 infected several million people of the world.

Developing easy to use and affordable screening tools would allow a considerable scale-up in testing. Transportable in size and straightforward in use, point-of-care (POC) systems could widen testing availability and specificity have been validated.

\section{Ideas Where the Research Go Next}

The recent epidemics caused by Zika virus and Middle East respiratory syndrome coronavirus (MERS-CoV) clearly illustrate the ability of emerging viruses to pose huge public health problems within a short time. Much more research effort is needed to understand the evolution and pathogenesis of these emerging viruses, as well as the development of diagnostics and therapeutics to combat existing and future epidemics [37-40].

\section{References}

1. Morse SS, Hughes JM (1996) Developing an integrated epidemiologic approach to emerging infectious diseases. Epidemiol Rev 18(1): 1-3.

2. Woolhouse ME, Gowtnge-Sequeria S (2005) Host range and emerging and reemerging pathogens. Emerg Infect Dis 11(12): 1842-1847.

3. Woolhouse M, Scott F, Hudson Z, Howey R, ChaseTopping M (2012) Human viruses: discovery and emergence. Philos Trans R Soc Lond B Biol Sci 367(1604): 2864-2871.

4. Howard CR (2012) Singapore: World Scientific Publishing, Lecture Emerging Viruses And human Health.

5. Lambrechts L, Paaijrnans KP, Fansiri T, Carrington LB, Kramer LD, et al. (2011) Impact of daily temperature fluctuations on dengue virus transmission by Aedcs aegypti. Proc Nati Acad Sci USA 108(18): 7460-7465.

6. Wearing HJ, Rohani P (2006) Ecological and immunological determinants of dengue epidemics. Proc Natl Acad Sci USA 103(31): 11802-11807.

7. Milazzo ML, Caymat MN, Duno G, Duno F, Utrera A, et al. (2011) Transmission of Guanarito and Pirital viruses among wild rodents, Venezuela. Emerg Infect Dis 17(12): 2209-2215.

8. Patz JA, Daszak P, Tabor GM, Aguirre AA, Pearl M, et al. (2004) Unhealthy landscapes: Policy recommendations on land use change and infectious disease emergence. Environ Health Perspect 112(10): 1092-1098.

9. Hufnagel L, Brockrnann, Geisel T (2004) Forecast and control of epidemics globalized world. Proc Natl Acad Sci USA 101(42): 15124-15129.

10. Hosseini P, Sokolow SH, Vandegrift KJ, Kilpatrick AM, Daszak P (2010) Predictive Power of air travel and socio-economic data for early pandemic spread. PLo5 One 5(9): e12763.

11. Mkar MA, Mohr O, Eckmanns T, Krause G (2012) Its G. Quantitative ti Passe flows in Europe and ts implications for tracing assessment of pa ng passengers Euro Surveil!.. 
12. Roehrig JT, Layton M, Smith P, Campbell GL, Nasci R, et al. (2002) emergence of West Nile virus in North America: ecology, epidemiology, and surveillance. Curr Top Microbiol Immunol 267: 223-240.

13. Campbell GL, Marfin AA, Lanciotti PS, Gubler DJ (2002) West Nile virus. Lancet Infect Dis 2(9): 519529.

14. Nemirov K, Henttonen H, Vaheri A, Plyusnin A (2002) Phylogenetic evidence for host switching in the evolution of hantaviruses carried by Apodemus mice. Virus Res 90(1-2): 207-215.

15. Morzunov SP, Rowe JE, Ksiazek TG, Peters CJ, St Jeor SC, et al. (1998) Genetic analysis of the diversity and origin of hantaviruses in Peromyscus leucopus mice in North America. J Virol 72(1): 57-64.

16. Vapalahti O, Lundkvist A, Fedorov V, Conroy CJ, Hirvonen S, et al. (1999) Isolation and characterization of a hantavirus from Lemmus sibiricus: evidence for host switch during hantavirus evolution. J Virol 73(7): 5586-5592.

17. Field H, de Jong C, Melville D, Smith C, Smith I, et al. (2011) Hendra virus infection dynamics in Australian fruit bats. PLoS One 6(12): e28678.

18. Wormer WH, Briggs DJ (2010) Rabies in the $21^{\text {st }}$ century. PLoS Negl Trop Dis 4(3): e591.

19. Wood TL, Leach M, Waldman L, Macgregor H, Fooks $A R$, et al. (2012) A framework for the study of zoonotic disease emergence and its drivers: spillover of bat pathogens as a case study. Philos Trans R 5oc Lond B Biol Sci 367 (1604): 2881-2892.

20. Negredo A, Palacios G, Vazquez-Moron S, González F, Dopazo H, et al. (2011) Discovery of an ebolaviruslike filovirus in europe. 1105 Pathog 7(10): e1002304.

21. Leroy EM, Kumulungui $B$, Pourrut $X$, Rouquet $P$, Hassanin A, et al. (2005) Fruit bats as reservoirs of Ebola virus. Nature 438(7068): 575-576.

22. Pourrut $X$, Kumulungui B, Wittmann T, Moussavou G, Délicat A, et al. (2005) The natural history of Ebola virus in Africa. Microbes Infect 7(7-8): 1005-1014.

23. Taylor DJ, Leach RW, Bruenn J (2010) Filoviruses are ancient and integrated into mammalian genomes. BMC Evol Biol 10: 193.
24. Balayan MS, Usmanov RK, Zamyatina NA, Djumalieva DI, Karas FR (1990) Brief report: experimental hepatitis $\mathrm{E}$ infection in domestic pigs. J Med Viral 32(1): 58-59.

25. Hsieh SY, Meng XJ, Wu YH, Liu ST, Tam AW, et al. (1999) Identity of a novel swine hepatitis E virus in Taiwan forming a monophyletic group with Taiwan isolates of human hepatitis E virus. J Clin Microbiol 37(12): 3828-3834.

26. Payne CJ, Ellis TM, Plant SL, Gregory AR, Wilcox GE (1999) Sequence data suggests big liver and spleen disease virus (BLSV) is genetically related to hepatitis E virus. Vet Microbiol 68(1-2): 119-125.

27. Huang FF, Haqshenas G, Guenette DK, Halbur PG, Schommer SK, et al. (2002) Detection by reverse transcription-PCR and genetic characterization of field isolates of swine hepatitis $E$ virus from pigs in different geographic regions of the United States. J Clin Microbiol 40(4): 1326-1332.

28. Miranda ME, White ME, Dayrit MM, Hayes CG, Ksiazek TG, et al. (1991) Seroepidemiological study of filovirus related to Ebola in the Philippines. Lancet 337(8738): 425-426.

29. Barrette RW, Metwally SA, Rowland JM, Xu L, Zaki SR, et al. (2009) Discovery of swine as a host for the Reston ebolavirus. Science 325(5937): 204-206.

30. Smith GT, Bahl J, Vijaykrishna D, Zhang J, Poon LL, et al. (2009) Dating the emergence of pandemic influenza viruses. Proc Natl Acad Sci USA 106(28): 11709-11712.

31. Kapoor A, Simmonds P, Gerold G, Qaisar N, Jain K, et al. (2011) Characterization of a canine homolog of hepatitis C virus. Proc Natl Acad Sci USA 108(28): 11608-11613.

32. Burbelo PD, Dubovi EJ, Simmonds P, Medina JL, Henriquez JA, et al. (2012) Serology-enabled discovery of genetically diverse hepaciviruses in a new host. J Viral 86(11): 6171-6178.

33. Stenglein MD, Sanders C, Kistler AL, Rubya JG, Francoa JY, et al. (2012) Identification, characterization, and in vitro culture of highly divergent arenaviruses from boa constrictors and annulated tree boas: candidate etiological agents for snake inclusion body disease. MBio 3(4): e00180-112. 
34. Khodakevich L, Jezek Z, Messinger D (1988) Monkeypox virus: ecology and public health significance. Bull World Health Organ 66(6): 747-752.

35. Centers for Disease Control and Prevention (CDC) (2003) Update: multistate outbreak of monkeypox-Illinois, Indiana, Kansas, Missouri, Ohio, and Wisconsin, 2003. MMWR Morb Mortal Wkly Rep 52(27): 642-646.

36. de Souza Trindade G, do Fonseca FG, Marques JT, Nogueira ML, Mendes LC, et al. (2003) Aracatuba virus: a vaccinialike virus associated with infection in humans and cattle. Emerg Infect Dis 9(2): 155-160.

37. Lau SKP (2018) Molecular Research on Emerging Viruses: Evolution, Diagnostics, Pathogenesis, and
Therapeutics. International Journal of Molecular Sciences 19(2): 398.

38. Ooi EE, Gubler DJ (2009) Dengue in Southeast Asia: epidemiological characteristics and strategic challenges in disease prevention. Cad Saude Publica 1: S115-124.

39. Gale P, Stephenson B, Brouwer A, Martinez M, de la Torre A, et al. (2012) Impact of climate change on risk of incursion of Crimean-Congo haemorrhagic fever virus in livestock in Europe through migratory birds. J April Microbial 112(2): 246-257.

40. Weiss RA, McMichael AJ (2004) Social and environmental risk factors in the emergence of infectious diseases. Nat Med 10(12): S70-76. 